\title{
Study on Colors of Modern Historical Buildings of Wuhan University Based on Munsell Color System
}

\author{
Ying Wang \\ School of Art and Design \\ Wuhan University of Science and Technology \\ Wuhan, China
}

\begin{abstract}
This paper states the construction and development of modern historical buildings of Wuhan University and analyzes basic color characteristics of them. Besides, this paper also points out the basic hue of these modern historical buildings apart from analyzing color composition and sameness and difference of them in terms of color through comparison. Moreover, artistic effects of color combination of these buildings are discussed too. On this basis, this study has implications for other researches on colors of modern buildings of campus of China.
\end{abstract}

Keywords-Wuhan University; architectural color; Munsell color system

\section{INTRODUCTION}

As we all know, Wuhan University is second to none among Modern Chinese campuses in terms of campus layout and building design. For overall designing and planning, Wuhan University properly combines geometrical patterns of western gardens and buildings and classical Chinese gardens according to geographical and cultural environment at that time. As a result, buildings in Wuhan University combines Chinese traditional culture symbols and western structural technology, which is a harmonious and perfect integration of Chinese and western cultures. Wuhan University is famous for "the most beautiful university in the world" not only because its graceful environment but also because its strong cultural atmosphere. At present, Wuhan University covers an area of $2,678,000 \mathrm{~m} 2$ of an overall area of $5187 \mathrm{mu}$. Thereinto, buildings constructed in 1930s are the quintessence of cultural landscape of Wuhan University for a hundred years and also masterpieces and models among campus buildings since modern times ${ }^{1}$. Moreover, the beautiful scenery of Luojia Hill and these early buildings echo each other at a distance, showing people a scenery line with aesthetic significance and historical value.

\section{CONSTRUCTION BACKGROUND OF MODERN} HISTORICAL BUILDINGS OF WUHAN UNIVERSITY

Historical buildings literally mean "buildings having a certain period of history", and are generally defined as

\footnotetext{
${ }^{1} \mathrm{Xu}$ Zhengpang. Cultural Value of Early Buildings of Wuhan University [J] Journal of Wuhan University, 2002.
}

historically commemorative buildings with a certain cultural value, research value, viewing value and artistic value. ${ }^{2}$ As the largest building group constructed in the Republican period, modern historical buildings of Wuhan University are relatively well preserved by far. In 1928, Cai Yuanpei appointed Li Siguang, a geologist, as the chairman of "Committee of Architectural Equipment for New School Buildings of National Wuhan University". In October 1929, F.H.Kales, an American architectural designer, was invited to design the new school buildings of Wuhan University. By March 1930, construction of buildings was completed mainly including five teaching buildings (respectively for colleges of agriculture, arts, science as well as law and engineering) and buildings with other functions such as library, gym, student dormitory, teachers' apartment, student canteen, clubs and laboratories. At that time, the campus covered an area of $213.33 \mathrm{~h} \mathrm{~m} \mathrm{~m}^{2}$, including 30 projects and 68 buildings. Such huge work amount created a masterpiece in architecture field in the modern history of China, which since then has been playing an important role in guiding the development of campus buildings. The building group of Wuhan University is the embodiment of social ideology in 1930s and also a reflection of material and spiritual civilization of that age.

\section{MUNSELl COLOR SYSTEM}

The Munsell color system was created by Professor Albert H. Munsell, an American chromatist, who published Munsell Book of Color in 1915, where he elaborates how to use algorism to explain colors. Through repeated measurement and amendment for several years, Optical Society of America (OSA) published Munsell Color System Amendment in 1943, which made the system an internationally-used standard color system $^{3}$.

The reason Munsell color system became an internationally-used standard color system is because color calibration method it shows is easy to understand. In the color system, there are 10 basic hues in the $360^{\circ}$ color sphere, including five principal hues: Red (R), Yellow (Y), Green (G),

\footnotetext{
${ }^{2}$ Wu Jie. Research on Construction and Restoration Technologies for Modern Historical Buildings of Wuhan University. Wuhan University of Technology, 2012

${ }^{3}$ Chen Feihu. Architectural Color [M]. Beijing: China Architecture and Building Press, 2007.
} 
Blue (B), and Purple (P), along with 5 intermediate hues halfway between adjacent principal hues, that is, Yellow-Red (YR), Green-Yellow (GY), Blue-Green (BG), Purple-Blue (PB) and Red-Purple (RP). According to the system, a color can be determined by three parameters: hue, value and chroma and this is a relatively accurate method to define and describe a color. Munsell use $\mathrm{HV} / \mathrm{C}$ as a standard formula to define a color, where $\mathrm{H}, \mathrm{V}$ and $\mathrm{C}$ represent hue, value and chroma respectively. Therefore, HV/C means hue, value/chroma. Besides, neutral colors, that is, black and white series colors, are represented by $\mathrm{N}$, followed by value $\mathrm{V}$ and no chroma after the slash. ${ }^{4}$

\section{ANALYSIS OF BASIC COLORS OF HISTORICAL BUILDINGS IN WUHAN UNIVERSITY}

\section{A. Analysis of Hues of Basic Colors of Historical Buildings in Wuhan University}

For studying the colors of historical buildings of Wuhan University, first, you have to determine their basic colors which are determined by the hues. Hue refers to the overall color of a picture, based on people's vision, called color effect. For the hue analysis, the library, administrative building (former building for engineering college) and Yinghua dormitory of Wuhan University are analyzed in detail, as main objects of the study. Detailed color parameters and patterns of the historical buildings of Wuhan University are shown in "Table I".

The symbol of historical buildings of Wuhan University has to be the one integrated point of aesthetic significance and cultural value - the old library, the exterior decoration of which combines with Chinese traditional culture, and the planning and design of its color are also distinctive. The roof adopts BG (5BG4/10) of high chroma as the basic hue and the vertical faces of the wall were painted earthy yellow with high value (2Y8/4) and reddish YR (5YR6/4) of medium chroma. Besides, the door is dark red of high value (5R4/12) and the window frame is gray of medium chroma (N4). As a whole, the unique color design of the exterior endows the library with naturalness and elegance, presenting the unique charm of the buildings of Wuhan University.

The administrative building grows out of the former building for the engineering college, each of the four corners of which has an annex which is lower than the main building. Facing the main building by their fronts, the four annexes are arranged symmetrically with four corners face each other. Different from those of the annexes, main color of roofs of the main building is peacock blue (5B4/10) while that of both of annexes and the old library is BG of high value (5BG4/10). Both sides of the right ahead of the main building are attached with a building with round roof that was painted ashy red of medium chroma (5R6/4). Walls of the administrative building are painted two colors with hues of gray: yellow of high value and low chroma $(2 \mathrm{Y} 8 / 4)$ and YR of high value and low chroma (7YR8/2), respectively. Much darker than that of walls, color of stairs is YR of medium-low value and chroma (3YR4/4). Area of window frames and doors is definitely much smaller than that of walls and roofs of the administrative building, so they are painted just for decoration, of which the window frames and the doors are painted gray (N4) and dark red of high chroma (5R4/12) respectively. Besides, based on the principle of axial symmetry, the main building and the annexes are well arranged and the four corners facing each other give people a sense of integrity. In the same way, colors of them are designed orderly and symmetrically, complementing the overall style of the administrative building.

Student dormitory (Laozhaishe) is surrounded by beautiful cherry trees is the earliest dormitory for students. The dormitory building is designed with some characteristics of western buildings, comprising four dormitory buildings whose roofs were painted with BG of high chroma (5BG4/10), just like roofs of other early history buildings. And some of the walls is grayish YR of high value and low chroma (6YR6/4), while the other walls are YR of higher value (7YR8/2), interspersed with gray (N4). Additionally, different with other buildings, the dormitory building has doors and windows frames painted the same color- dark red of low value and high chroma (5R4/12). On the whole, the design of student dormitory building highlights its elegance and calmness, and 100 uniform stairs built at the entrance of the dormitory building are grand and magnificent.

\section{B. Components of Colors of Historical Buildings in Wuhan University}

Colors of historical buildings of Wuhan University are mainly divided into two parts: one is weight sense of color and the other is area of color.

Weight sense of color is mainly determined by the value of color. For example, light colors always give people a sense of light weight and softness, and on the contrary, dark colors always make people feel more pressured and heavy. In historical buildings of Wuhan University, most roofs are BG $(5 \mathrm{BG} 4 / 10)$ and roofs of main building of the administrative building are peacock blue (5B4/10). The value of the two colors is 4 , which is considered as medium-low. Window frames, doors and stairs in the administrative building are gray (N4), dark red (5R4/12) and YR (3YR4/4), respectively, with the same value of 4 . Besides, most walls of the history buildings are painted in yellow (2Y8/4) and YR (5YR6/4, $7 Y R 8 / 2$ and 6YR6/4), with a value of 6 or 8 . Such color design reveals that building components such as roofs, walls, window frames and doors are mainly painted in colors with lower value, which can give people a sense of slight solemn, while walls are mainly designed with colors of higher value to create a soft atmosphere.

The area of color refers to the percentage of a color covered area to the overall area of the building. "Table II" shows detailed analysis.
Wan Xuan. Study on Color Planning of Buildings of New

Countryside of Sichuan Based on Munsell Color System-Color Planning of Rural Residential Buildings of Beichuan Qiang 
TABLE I. EXTRACTED COLORS OF LIBRARY, ADMINISTRATIVE BUILDING AND STUDENT DORMITORY OF WUHAN UNIVERSITY (MADE By THE AUTHOR)

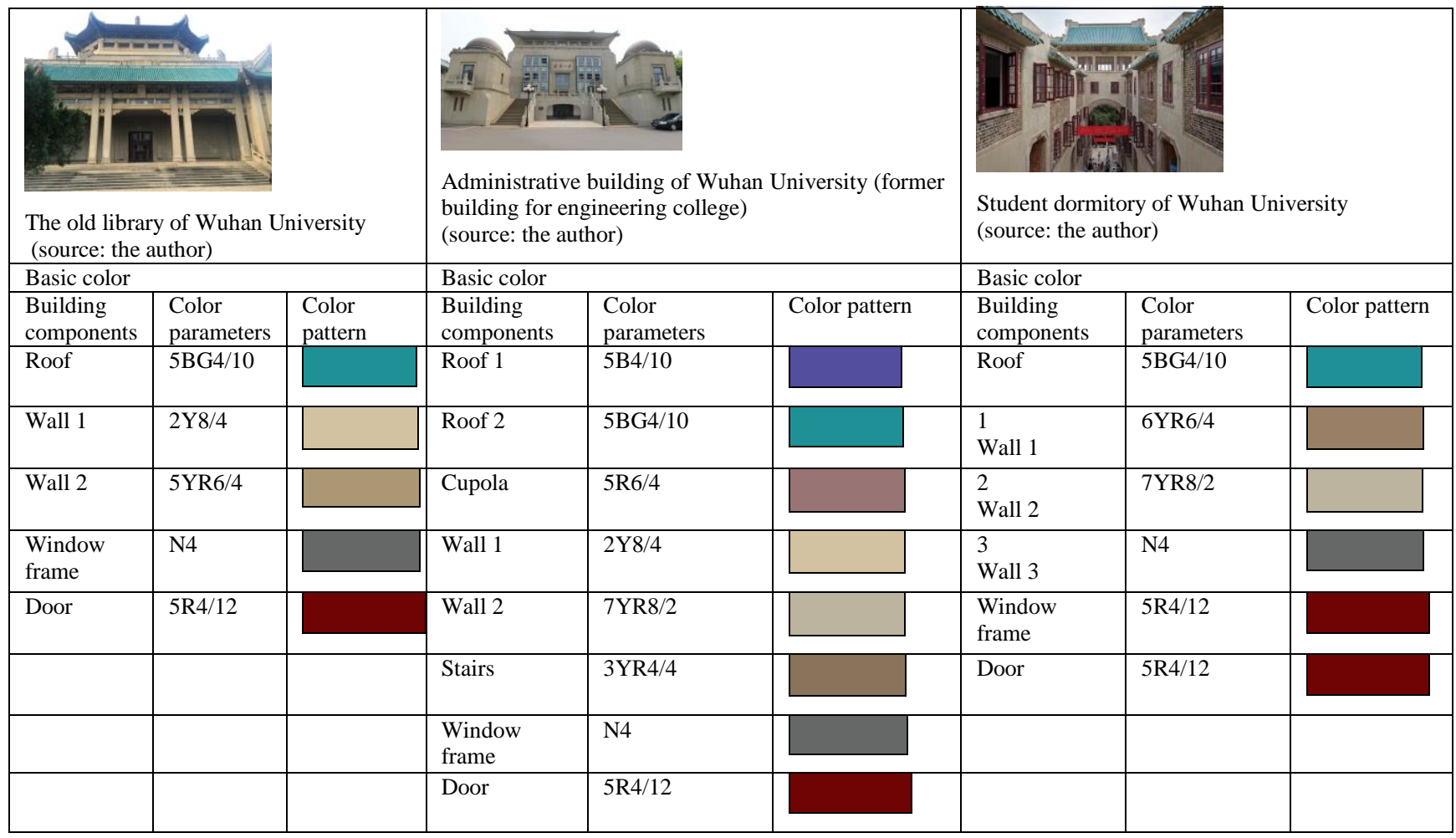

TABlE II. Percentage of A Color Covered Area to the Overall Area of the Building (Source: The Author)

\begin{tabular}{|l|l|l|l|l|l|l|l|}
\hline \multicolumn{2}{|l|}{ The old library } & \multicolumn{3}{l|}{ Administrative building } & \multicolumn{2}{l|}{$\begin{array}{l}\text { Students } \\
\text { building }\end{array}$} \\
\hline Color pattern & Percentage & \multicolumn{2}{|l|}{ Color pattern } & Percentage & Color pattern & Percentage \\
\hline & $20 \%$ & & & & & \\
\hline \\
\hline
\end{tabular}

\section{Comparison of Colors of Historical Buildings in Wuhan} University

Contrasting color is one of physiological phenomenon produced by the sense of sight of people, which refers to colors within $120^{\circ}-180^{\circ}$ in the 24 -color sphere. This paper mainly involves complementary colors, adjacent colors and contrasting colors. Complementary color pairs include redgreen, blue- orange and purple- yellow, and characteristics of complementary color pairs are skillfully exerted into the color design of the historical buildings of Wuhan University. The most classic example is the design of colors of roofs and doors of a building. That is, the roofs are blue-green and doors are dark red, and the two colors are the most classic complementary color pair. Blue-green roofs and yellow-red roofs present that blue and orange is a pair of contrasting colors. In the color design of administrative building, purple roofs and earthy yellow walls echo each other. In the design of color area, the best scheme is that one color is dominant with the other complementary color as decoration. Such skill is 
fully used in the design of the historical buildings of Wuhan University.

Adjacent colors are a pair of colors closest to each other in the color sphere, such as purple-blue and green-yellow. Adjacent colors always contain each other and the design of blue-green roofs and yellow-red walls just uses such characteristic. For instance, roofs of the main building of the administrative building are purple and those of the annexes are blue-green. Such combination of colors is harmonious, as purple and blue-green are also adjacent colors.

The contrasting colors mainly refer the greatly difference in values and chromas of colors. Change of value and chroma of color is the critical factor directly influencing people's feeling to colors. For example, roofs painted in blue-green of low value and high chroma contrast sharply with walls painted in colors of high value and low chroma, making the whole picture more uniform and harmonious.

\section{Artistic Effect of Colors of Historical Buildings in Wuhan University}

Area effects: large areas are painted in colors of low chroma, while small areas are pained in colors of high chroma or in an interspersed way. In terms of utilization of color area, F.H.Kales makes a perfect planning and utilization of colors for buildings. Walls covering a large area are painted in yellow and yellow-red both of low chroma, and on the contrary, roofs, window frames and doors, which cover a small area, are painted in blue-green and dark red. Such design prevents people from fatigue when they looking at these colors for a long time, as the color combination creates a soft visual effect.

Emotional effect: hue, value and chroma can influence the emotional effects of colors, of which hue is a factor having direct influence. Among colors of buildings of Wuhan University, the most representative color is blue-green, color of roofs. On seeing blue, people always associate it with ocean, a symbol of limitless knowledge; green represents peace and hope, showing the university's academic attitude and belief. In addition, roofs of cold tone gives people a sense of saneness and calmness. Blue-green is not only a color for building decoration but also the belief of teachers and students of the university in teaching, academics and the whole life. Yellow, the color of walls, represents resplendency and mysteriousness, symbolizing the power of knowledge, mysterious but splendid. And dark red, the color of windows and doors, stands for Chinese traditional culture and enthusiasm and also a symbol of regional and cultural characteristics. As a symbol of mental outlook of Wuhan University, every color of its buildings was chosen through deep consideration.

\section{CONCLUSION}

All historical buildings of Wuhan University have a style of their own, whether library or students dormitory. In terms of color composition, most of building components such as roofs, window frames and doors are painted in colors of low value, except walls which are painted in colors of high value. In terms of color area, area of colors of walls takes the highest proportion over the overall area of the whole building, followed by roofs, then by window frames and doors. In color contrasting, roofs and doors, roofs and walls, as well as roofs and walls of the main building of the administrative building, the three pairs of building components are painted in three pairs of contrasting colors respectively; Roofs, walls, roofs of the main building of the administrative building and the four annexes are painted adjacent colors; Color of low value and high chroma for roofs and color of high value and low chroma for walls shows the application of contrasting colors. In terms of the area effect, large areas are painted in colors of low chroma, while small areas are pained in colors of high chroma. In terms of emotional effects, blue-green, color of roofs, stands for an academic attitude and belief; yellow, color of walls symbolizes the power of knowledge, mysterious but splendid; dark red, color of windows and doors, stands for regional and cultural characteristics. Through deep research on colors of historical buildings, this paper analyzes the composition, comparison and artistic effects of colors, aiming to enrich people's design ideas and directions and give them some inspiration in building color design.

\section{REFERENCES}

[1] Xu Zhengpang. Cultural Value of Early Buildings of Wuhan University [J]. Journal of Wuhan University, 2002.

[2] Wu Jie. Research on Construction and Restoration Technologies for Modern Historical Buildings of Wuhan University. Wuhan University of Technology, 2012.

[3] Fuxin. The Architecture History of Historical Architecture of Wuhan University. Architectural History, 2009.

[4] Wan Xuan. Study on Color Planning of Buildings of New Countryside of Sichuan Based on Munsell Color System - Color Planning of Rural Residential Buildings of Beichuan Qiang Autonomous County [J]. Sichuan Building Science, 2013.

[5] Chen Feihu. Architectural Color [M]. Beijing: China Architecture and Building Press, 2007.

[6] Li Xiangbei, Wang Jinyao, Fan Peng-Study on Colors of Traditional Domestic Architecture of Bai Nationality, Xizhou Town, Dali, Yunnan-A Case Study of Yan's Grand Courtyard [J]. Studies in National Art, 2013, 6:133-137.

[7] Ding Hao. Application of Colors in Architectural Design [J].Anhui Architecture, 2008 (1).

[8] Ma Jing. Analysis and Research on the Application of Colors in Buildings of New Countryside West of Sichuan Based on Munsell Color System [J]. Sichuan Building Science, 2015.

[9] Jiao Yan. The Display and Design of Architectures' Outside Color [M]. Beijing: China Machine Press, 2001.

[10] Huang Deming. Characteristics of Art of Gardening of Early Buildings of Wuhan University. Planners, 2003(9). 